\title{
Consenvación In Vitro de Dos Variedades de Papa (Solanum tuberosum L) Bajo Condiciones de Crecimiento Mínimo
}

\author{
Josefina Páez de Cásares, Roberto González ${ }^{1}$
}

\begin{abstract}
Resumen
Para desarrollar una metodología que permita mantener y conservar plántulas de papa (Solanum tuberosum L) se llevaron a cabo dos ensayos bajo condiciones de crecimiento mínimo con las variedades Kennebec y Patrones. Nudos de $1 \mathrm{~cm}$ de longitud fueron establecidos in vitro y al azar en diferentes medios de cultivo conteniendo el medio base Murashige y Skoog (1962) y variando los siguientes constituyentes: Manitol (\%), Sacarosa (\%), Agar (\%), Bencilaminopurina (BAP) (mg/l), Ácido Abscísico (ABA) $(\mathrm{mg} / \mathrm{l})$ y Cloruro de clorocolina (CCC) $(\mathrm{mg} / \mathrm{l})$. Se evaluaron seis tratamientos $(T)$ en las siguientes proporciones de acuerdo al orden previo: T1 (4, 3, 0.8, 0, 0, 0); T2 (4, 3, 0.8, 0, 1.5, 1.5); T3 (2, 3, 0.8, 0, 1.5, 1.5); T4 (2, 3, 0.8, 1.5, 0, 0); T5 (2, 2, 0.8, 1.5, 0, 1.5); T6 (4, 0.5, 0.8, 0, 0, 0). Las plántulas crecieron bajo condiciones de $2 \mu \mathrm{mol} / \mathrm{m}^{2} / \mathrm{s}$ (2000 lux) por $12 \mathrm{~h} \mathrm{a}$ $20 \pm 2^{\circ} \mathrm{C}$ y $50-80 \%$ de humedad relativa. Se realizaron evaluaciones frecuentes durante 5 meses. En el quinto mes, la variedad Kennebec presentó menor altura y número de raíces en los tratamientos $T_{3}$ y $T_{5}$ esperándose que garantice una conservación por mayor tiempo, mientras que, la variedad Patrones presentó la misma respuesta en los tratamientos $T_{2} y_{6}$. En una segunda fase se evaluará si las plantas con menor altura y número de raíces son las que resisten el almacenamiento por un mayor tiempo.
\end{abstract}

Palabras claves adicionales: Conservación in vitro, nudos, crecimiento mínimo, Solanum tuberosum.

\footnotetext{
${ }^{1}$ Laboratorio de Cultivo de Tejidos del Instituto de Agronomía, Facultad de Agronomía, Universidad Central de Venezuela, Apartado 4579-A, Maracay 2101, Venezuela.
} 


\title{
In Vitro Storage of Two Potato Varieties (Solanum tuberosum $L$ ) Under Minimal Growth Conditions
}

\begin{abstract}
Summary
In order to develop a methodology to maintain and store potato varieties (Solanum tuberosum $\mathrm{L}$ ) two experiments were set under minimal growth conditions with two potato varieties Kennebec USA and Patrone USA. Microcuttings $1 \mathrm{~cm}$ long were planted at random in vitro, in different culture media containing Murashige Skoog's (1962) basic salts, with various concentrations of the following components: mannitol (\%), sucrose (\%), agar (\%), benzylaminopurine (BAP) (mg/l), abscicic acid (ABA) (mg/l) and chlorocholine chloride (CCC) $(\mathrm{mg} / \mathrm{l})$. Six treatments $(\mathrm{T})$ in the following proportions were evaluated and follow the same order as substances were named: T1 (4, 3, 0.8, 0, 0, 0); T2 (4, 3, 0.8, 0, 1.5, 1.5); T3 (2, 3, 0.8, 0, 1.5, 1.5); T4 (2, 3, 0.8, 1.5, 0, 0); T5 (2, 2, 0.8, 1.5, 0, 1.5); T6 (4, 0.5, 0.8, 0, 0 , 0 ). Microcuttings planted were exposed to $2 \mu \mathrm{mol} / \mathrm{m}^{2} / \mathrm{s}$ (2000 lux) for $12 \mathrm{~h}$ at $20 \pm 2^{\circ} \mathrm{C}$ and $50-80 \%$ relative humidity. The evaluation period lasted five months. Kennebec USA microcuttings under T3 and T5 showed a tendency to be shorter in length as well as to develop a fewer roots. This, in fact, insured prolonged storage. Similar results showed Patrones USA microcuttings under T2 and T6 treatments. Research will continue to test if smaller plants with fewer roots are able to withstand a longer-term storage.
\end{abstract}

Additional Index words : In vitro storage, microcuttings, minimal growth, Solanum tuberosum

\section{Introducción}

La papa (Solanum tuberosum $\mathrm{L}$ ) normalmente es propagada vegetativamente. El método de crecimiento mínimo in vitro es uno de los más utilizados y constituye una alternativa de las técnicas del cultivo de tejidos para mantener plántulas en mejores condiciones sanitarias. 
Mediante esta técnica se obtiene un estricto control sobre plagas y enfermedades al encontrarse el material confinado en un microambiente aséptico, también el sistema ocupa muy poco espacio y al propagarse clonalmente permite el mantenimiento del genotipo $(7,8)$.

Con el presente trabajo se ha querido lograr una metodología que permita evaluar y conservar variedades de papa (Solanum tuberosum L) para asegurar el mantenimiento de dicho material por largos periodos.

La papa es uno de los cultivos más estudiados y versátiles en los últimos años en la implementación de nuevos medios y técnicas de cultivo de tejidos, que permitan el desarrollo de plantas completas y sanas a partir de meristemas apicales, yemas axilares, segmentos nodales, raíces, tubérculos, protoplastos y células cultivadas in vitro $(1,3,4,6,9,10)$.

La conservación in vitro en papa se logra bajo la utilización de dos técnicas diferentes, por medio de la limitación del crecimiento hasta tasas mínimas (Conservación in vitro) o la supresión total del metabolismo celular (Criopreservación) (1). En papa, se ha comprobado que los cultivos de yemas, mantenidos a $9-10^{\circ} \mathrm{C}$ permanecen viables durante un año (11) y si esa temperatura disminuye a $6-8^{\circ} \mathrm{C}$ pueden mantenerse hasta períodos de 3 a 5 años (2).

Henshaw et al, referidos por Lindsey (4), encontraron en cultivos de meristemas Solanum spp, que el nivel de sobrevivencia se incrementó a un $83 \%$ cuando las temperaturas diurna y nocturna fueron de $12^{\circ} \mathrm{C}$ y $6^{\circ} \mathrm{C}$, respectivamente. Por otra parte, se ha logrado extender el período de transferencia de ápices caulinares de papa cuando la temperatura es reducida y se favorece la sobrevivencia cuando se incrementa el volumen del medio y la concentración de sacarosa (12). También se comprobó que se podía aumentar la tasa de sobrevivencia a un $60 \%$ después de 12 meses, combinando ácido abscísico y manitol en el medio (13). Mientras que Warham et al (11) pudieron establecer las condiciones óptimas de conservación in vitro de algunos cultivares de papa. Encontraron que a $10^{\circ} \mathrm{C}$ bajo 500-1,000 Lux por 18 horas /día y añadiendo manitol al medio se lograba un $90-100 \%$ de viabilidad al material vegetal.

En Venezuela se ha trabajado especialmente en la producción de tubérculossemilla con el objetivo de producir plantas y microtubérculos (Perdomo y Páez de Cásares, 1990), además, la inducción de tuberización in vitro con el uso de CCC (Vásquez y Páez de Cásares, 1989). En el presente trabajo se desea aportar en el mejoramiento de medios de cultivo y condiciones de conservación in vitro en dos variedades de papa. 


\section{Materiales y Métodos}

Los ensayos se realizaron en el Laboratorio de Propagación de Plantas y la Unidad de Apoyo de Cultivo de Tejidos del Instituto de Agronomía de la Facultad de Agronomía, Universidad Central de Venezuela, Núcleo Maracay, Estado Aragua, Venezuela.

Se utilizaron plantas establecidas in vitro provenientes del ínter Regional Potato Introduction Station de Estados Unidos libres de algunas plagas y enfermedades (los virus $A, X, S, M, Y, y$ el viroide PLRV) y pertenecientes a los cultivares Kennebec y Patrones cultivadas por varias generaciones. La primera fue efectuada de enero-mayo y el segundo de abril-agosto de 1994, respectivamente.

\section{Metodología}

Se procedió a seleccionar plantas in vitro, que presentaron uniformidad en tamaño y vigor, llevándolas a la cámara de flujo laminar, previamente esterilizada, donde se seccionaron en nudos de $1 \mathrm{~cm}$ de longitud tomados de la parte media de las plantas, desprovistas de la yema apical, hojas y raicillas. La implantación aséptica se realizó en diferentes medios de cultivo. Fueron utilizados tubos de ensayos de $150 \mathrm{~mm} \times 20 \mathrm{~mm}$, que contenían $20 \mathrm{mi}$ del medio básico de Murashige y Skoog de 1962 suplementado con los constituyentes orgánicos: Sacarosa, Manitol y Agar expresado en porcentaje entre paréntesis, las hormonas y retardantes de crecimiento Bencil aminopurina (BAP), Ácido Ábscisico (ABA) y Cloruro de clorocolina (CCC) en $\mathrm{mg} / \mathrm{l}$ entre paréntesis, respectivamente: $\mathrm{M}_{1}(3,4,0.8,0,0,0) ; \mathrm{M}_{2}(3,4,0,8,0,1.5,1.5) ; \mathrm{M}_{3}(3,2,0.8,0$, $1.5,1.5) ; \mathrm{M}_{4}(3,2,0.8,1.5,0,0) ; \mathrm{M}_{5}(2,2,0.8,0,1.5,1.5)$ y $\mathrm{M}_{6}(0.5,4,0.8,0$, $0,0)$.

El pH fue ajustado a 5.7-5.8 y los tubos una vez sellados con papel transparente "Envoplast" fueron incubados en un cuarto climático por 5 meses bajo condiciones ambientales controladas de $20 \pm 2{ }^{\circ} \mathrm{C}, 50-80 \%$ de humedad relativa, 2 $\mu \mathrm{mol} / \mathrm{m}^{2} / \mathrm{s}$ (aproximadamente 2,000 lux de intensidad de luz) por 12 horas/día. 
El diseño utilizado fue completamente al azar, constituido por 6 tratamientos, tres plantas como unidad experimental y 6 repeticiones.

Se realizaron evaluaciones mensuales de: número de raíces, tamaño de la raíz más larga $(\mathrm{cm})$, diámetro del callo $(\mathrm{cm})$, altura de la parte aérea $(\mathrm{cm})$, número de nudos, color: mediante una escala (verde normal: 3; verde claro: 2. amarillento: $1)$, contaminación por hongos $(\mathrm{H})$ y bacterias $(B)$.

\section{Resultados y Discusión}

\section{Ensayo 1 (Cultivar Kennebec)}

Transcurridos los primeros días del ensayo, se hizo notoria la presencia de hongos en el $\mathrm{T}_{1}$, el cual tuvo que ser eliminado al poco tiempo, por esa razón no se cuenta con información del mismo.

En el estudio del número de raíces formadas, se observaron diferencias significativas entre los tratamientos $\mathrm{T}_{2}, \mathrm{~T}_{4}$ y $\mathrm{T}_{6}$, mostraron una misma tendencia respecto a la variable en estudio, destacando el $\mathrm{T}_{4}$ a los 5 meses, momento en el cual culminó el ensayo. También se observó, que los tratamientos $T_{3}$ y $T_{5}$ presentaron una menor altura de plántulas (Tabla 1). Estos últimos tratamientos tienen en el medio menos concentración de azúcares y contienen ABA y CCC produciendo un efecto en la disminución de crecimiento. A pesar que $T_{2}$ contenía los mismos inhibidores de crecimiento su efecto fue contrarrestado con la presencia de mayor concentración de azúcares (3\% sacarosa y 4\% manitol).

Con respecto a la altura de las plántulas, se pudieron constatar diferencias significativas entre los tratamientos (Tabla 1), apreciándose que los que presentaron un menor desarrollo radical también mostraron el menor desarrollo del tallo y número de nudos al quinto mes de la implantación. Mientras que el $\mathrm{T}_{4}$, al que no se le suministró retardante de crecimiento en el medio, presentó un desarrollo aéreo y radical significativamente mayor que los restantes tratamientos, así como también del callo en la base de los nudos. 
Tabla 1. Valores promedio observados en plántulas de papa (Solanum tuberosum $L$ ) var. Kennebec provenientes de nudos conservados in vitro a los 5 meses de implantados.

\begin{tabular}{|clllll|}
\hline Tratamiento $^{z}$ & $\begin{array}{c}\text { Número de } \\
\text { raíces }\end{array}$ & $\begin{array}{l}\text { Longitud raíz } \\
\text { más larga }(\mathrm{cm})\end{array}$ & Callo $(\mathrm{cm})$ & $\begin{array}{c}\text { Altura de } \\
\text { planta }(\mathrm{cm})\end{array}$ & $\begin{array}{c}\text { Número } \\
\text { de nudos }\end{array}$ \\
\hline $\mathrm{T}_{2}$ & $5.0 \mathrm{ab}$ & $2.54 \mathrm{ab}$ & $0.0 \mathrm{~b}$ & $6.60 \mathrm{ab}$ & $6.60 \mathrm{ab}$ \\
$\mathrm{T}_{3}$ & $2.5 \mathrm{~b}$ & $0.66 \mathrm{~b}$ & $0.07 \mathrm{ab}$ & $2.33 \mathrm{~b}$ & $3.57 \mathrm{~b}$ \\
$\mathrm{~T}_{4}$ & $6.4 \mathrm{ab}$ & $3.9 \mathrm{a}$ & $0.76 \mathrm{a}$ & $7.0 \mathrm{a}$ & $7.8 \mathrm{~b}$ \\
$\mathrm{~T}_{5}$ & $1.15 \mathrm{~b}$ & $0.55 \mathrm{~b}$ & $0.04 \mathrm{ab}$ & $1.75 \mathrm{~b}$ & $2.92 \mathrm{~b}$ \\
$\mathrm{~T}_{6}$ & $4.4 \mathrm{ab}$ & $2.26 \mathrm{ab}$ & $0.0 \mathrm{~b}$ & $4.3 \mathrm{ab}$ & $10.8 \mathrm{a}$ \\
\hline
\end{tabular}

Medias en la misma columna seguidas de la misma letra no difieren significativamente (M.D.S. al 5\%)

${ }^{2} \mathrm{~T}_{2}$ (3\% Sac- 4\% Man- 0.8\% Agar- 1,5mg/l ABA-1.5mg/l CCC)

$\mathrm{T}_{3}$ (3\% Sac- 2\% Man- 0.8\% Agar- 1,5rmg/l ABA-1.5mg/l CCC)

$\mathrm{T}_{4}$ (3\% Sac- $2 \%$ Man- $0.8 \%$ Agar- $\left.1,5 \mathrm{mg} / \mathrm{BAP}\right)$

$\mathrm{T}_{5}$ (2\% Sac- $2 \%$ Man- $0.8 \%$ Agar- $1,5 \mathrm{mg} / \mathrm{l}$ ABA-1.5mg/l CCC)

$\mathrm{T}_{6}(0,5 \%$ Sac-4\% Man- 0.8\% Agar)

\section{Ensayo 2 (Cultivar Patrones)}

Las plantas del tratamiento $T_{5}$, a los cinco meses (Tabla 2) mostraron significativamente mayor número y longitud de raíces; le siguieron los tratamientos $T_{1}, T_{4} T_{6}$ y $T_{3}$. También se observaron diferencias significativas en las plántulas del $\mathrm{T}_{2}$, el cual por el efecto de los inhibidores de crecimiento y el exceso de azúcares presentes en el medio, retardó el número y longitud de las raíces. De igual manera, se apreció durante los primeros cinco meses un mayor crecimiento en la altura de las plántulas y número de nudos en el tratamiento $T_{5}$ (Tabla 2).

Las plántulas con una mayor altura $\left(T_{5}\right)$ alcanzaron un promedio de $6.15 \mathrm{~cm}$ al final del experimento, así como un mayor número de nudos (12.62) de manera que se encontró una cantidad mayor de entrenudos más cortos. Es importante señalar la tendencia del tratamiento $\mathrm{T}_{3}$ de promover el desarrollo de plántulas vigorosas y de hojas de color verde. Los otros tratamientos presentaron plantas con tallos muy delgados, aunque con hojas de color verde con buena apariencia. Poco desarrollo de callo se observó en la base de los nudos y sólo el $\mathrm{T}_{4}$ presentó uno muy pequeño (Cuadro 2). En este mismo tratamiento también se pudo observar la formación de microtubérculos. 
Tabla 2. Valores promedio observados en plántulas de papa (Solanum tuberosum $L$ ) var. Patrones provenientes de nudos conservados in vitro a los 5 meses de implantados

\begin{tabular}{|clllll|}
\hline Tratamiento $^{z}$ & $\begin{array}{c}\text { Número } \\
\text { de raíces }\end{array}$ & $\begin{array}{c}\text { Longitud raíz } \\
\text { más larga }(\mathrm{cm})\end{array}$ & $\begin{array}{c}\text { Callo } \\
(\mathrm{cm})\end{array}$ & $\begin{array}{c}\text { Altura de } \\
\text { planta }(\mathrm{cm})\end{array}$ & $\begin{array}{c}\text { Número de } \\
\text { nudos }\end{array}$ \\
\hline $\mathrm{T}_{1}$ & $3,61 \mathrm{ab}$ & $3,02 \mathrm{ab}$ & $0,0 \mathrm{~b}$ & $3,82 \mathrm{ab}$ & $7,67 \mathrm{ab}$ \\
$\mathrm{T}_{2}$ & $0,22 \mathrm{~b}$ & $0,14 \mathrm{c}$ & $0,0 \mathrm{bc}$ & $0,79 \mathrm{c}$ & $3,89 \mathrm{~b}$ \\
$\mathrm{~T}_{3}$ & $1.50 \mathrm{ab}$ & $0,86 \mathrm{~b}$ & $0,0 \mathrm{bc}$ & $3,38 \mathrm{ab}$ & $7,83 \mathrm{ab}$ \\
$\mathrm{T}_{4}$ & $3,50 \mathrm{ab}$ & $1,68 \mathrm{ab}$ & $0,61 \mathrm{a}$ & $4,02 \mathrm{ab}$ & $7,06 \mathrm{ab}$ \\
$\mathrm{T}_{5}$ & $4,77 \mathrm{a}$ & $3,73 \mathrm{a}$ & $0,0 \mathrm{bc}$ & $6,15 \mathrm{a}$ & $12,62 \mathrm{a}$ \\
$\mathrm{T}_{6}$ & $2,28 \mathrm{ab}$ & $1,38 \mathrm{ab}$ & $0,0 \mathrm{bc}$ & $2,61 \mathrm{~b}$ & $6,33 \mathrm{~b}$ \\
\hline
\end{tabular}

Medias en la misma columna seguidas de la misma letra no difieren significativamente (M.D.S. al 5\%)

${ }^{2} \mathrm{~T}_{1}$ (3\% Sac- 4\% Man-0,8\% Agar)

$\mathrm{T}_{2}$ (3\% Sac- $4 \%$ Man- $0.8 \%$ Agar- $1,5 \mathrm{mg} / \mathrm{l}$ ABA-1.5mg/l CCC)

$\mathrm{T}_{3}$ (3\% Sac- $2 \%$ Man- $0.8 \%$ Agar- 1,5mg/l ABA-1.5mg/l CCC)

$\mathrm{T}_{4}$ (3\% Sac- $2 \%$ Man- $0.8 \%$ Agar- 1,5mg/l BAP)

$\mathrm{T}_{5}$ (3\% Sac- 2\% Man- 0.8\% Agar- 1,5mg/l ABA-1.5mg/l CCC)

$\mathrm{T}_{6}$ (0,5\% Sac- $4 \%$ Man- $0.8 \%$ Agar)

\section{Conclusiones}

* En el ensayo con la var. Kennebec, a pesar de haberse perdido el tratamiento $\mathrm{T}_{1}$ por contaminación, se pudo observar que los tratamientos $T_{3}$ y $T_{5}$ presentaron moderado desarrollo aéreo y radical para la conservación bajo crecimiento mínimo. En tanto los tratamientos $T_{2}, T_{4}$ y $T_{6}$ presentaron mayor altura y número de raíces que los citados anteriormente.

* Para el ensayo con la var. Patrones, se pudo observar que los tratamientos $T_{2}$, $\mathrm{T}_{3}$ y $\mathrm{T}_{6}$ fueron los que presentaron una moderada altura y raíces para la conservación bajo crecimiento mínimo, apreciándose además una mayor altura y número de raíces en $T_{1} T_{4}$ y $T_{5}$.

* La respuesta a los tratamientos como se pudo observar varió de acuerdo al cultivar utilizado. 


\section{Agradecimiento}

Agradecemos al Consejo Nacional de Investigaciones Científica y Tecnológica (CONICIT), a la Universidad Central de Venezuela (Facultad de Agronomía y al Consejo de Desarrollo y Humanístico, $\mathrm{CDCH}$ ) el financiamiento para realizar el presente trabajo. Al Ínter-Regional Potato Introduction Station de Estados Unidos por el suministro del material vegetal utilizado en esta investigación.

\section{Referencias Bibliográficas}

1. Bajaj, Y. 1981. Regeneraron of plants from potato meristems freezepreserved for 24 months. Euphytica 30: 141-135.

2. Golmirzaie, A.; Toledo, J. Noncryogenic, long term germoplasm storage. Methods in molecular Biology. En: Vol III: Plant Cell culture protocols, Ed. R. D. Hall Human Press Inc. Totowa, N. J. p. 95-101.

3. Hussey, G.; Stacey, N. 1981. In vitro propagation of potato. Am. Botany 48: 787-796.

4. Lindsey, A. 1980. Tissue culture storage for genetic conservation IBPGR. Technical Report. Rome. 14 p.

5. Murashige, T.; Skoog, F. 1962. A revise medium for rapid growth and bioassays with tobaco tissue culture. Physiology PL. 15:473-496-

6. Perdomo, D.; Páez de Cásares, J. 1989. Avance en la producción de plantas in vitro a partir de ápices caulinares de papa. Revista de la Facultad de Agronomía de la Universidad Central de Venezuela. Alcance $N^{Q} 38,109-119$.

7. Roca, M.; Mroginski, L. 1991. Cultivo de Tejidos en la Agricultura. Fundamentos y Aplicaciones. CIAT, Colombia. 697p.

8. Slack, S. 1980. Meristem tip culture. Plant Disease 64 (1): 15-17.

9. Stace-Smith, R; Mellor, C. 1968. Erradication of potato viruses $X$ and $S$ by thermotherapy and axillary bud cultures. Phytopathology 58(2): 199-203.

10. Vásquez, R.; Páez de Cásares, J. 1989. Producción in vitro de brotes aéreos de papa (Solanum tuberosum L) cv. Atzimba. Revista de la Facultad de Agronomía de la Universidad Central de Venezuela. Alcance $N^{\circ} 28,119-130$.

11. Warham, E.; Burnett, P. 1989. In vitro storage of potato. ZuowupinzbongZiyuan N 3, 42-43.

12. Wescott, R.J. 1981. Tissue culture storage of potato germplasm I. Minimal growth storage. Potato Res. 24: 341-342. 
13. Wescott, R.J. 1981. Tissue culture storage of potato germplasm 2. Use of growth retardants. Potato Res. 24: 343-352. 